\title{
Evolution of a medical waste disposal bag into a low cost personal protective equipment during COVID-19 pandemic
}

\section{Udaya Nandimittra de Silva}

Teaching Hospital Anuradhapura, Ministry of Health, Sri Lanka

Correspondence: dsudaya@gmail.com

DOI: https://doi.org/10.4038/jccpsl.v26i5.8325

https://orcid.org/0000-0002-3694-4543

Received on 9 May 2020

Accepted on 23 June 2020

\begin{abstract}
Summary
COVID-19 pandemic is a global public health challenge. It is caused by SARS-CoV-2 virus transmitted via droplets and contact through surfaces contaminated with the virus. To prevent, the use of appropriate personal protective equipment (PPE) is essential during handling of confirmed patients and suspects. Ensuring an uninterrupted supply chain of PPE will protect the healthcare providers who are at highest risk of contracting the disease (1). However, shortage of PPE has been a common problem in many countries including in Sri Lanka (2-4). This situation is unacceptable with regard to the safety of healthcare workers. In this background, locally designed new innovations on PPEs are effective alternatives to face the challenge (3). This narrative report highlights the importance of preparedness and the usefulness of new innovations. As a developing country, low cost alternatives for popular high cost products should be encouraged.
\end{abstract}

\section{Public health response and its impact}

On 2 March 2020, an eight-month old baby was admitted to Teaching Hospital, Anuradhapura after arrival from Milano, Italy with fever and respiratory distress. By this time, there had been a large number of cases reported in this city including many deaths. With less previous experience related to the illness, the paediatric team promptly moved the patient to the isolation unit and arranged to adopt standard safety precautions, such as before entering the isolation unit, each team member was required to wear PPE, including medical masks, respirators, gloves, gowns and eye protection. Along with it, the anxiety of being self-infected with COVID-19 and the challenge of managing the suspected disease made it a complicated and brand-new experience for the whole team. Further, dressing up as well as removal of PPE (doffing) was an extremely difficult procedure for the team. The gowns used were not waterproof, while the head and foot covers were caps and shoe covers used in ordinary operation theatres. Also, the cost of PPE was several thousand rupees.

With the progressive spread of COVID-19 infection, the demand for PPE increased island wide. Many 
started manufacturing their own protective garments due to lack of supply to meet the heavy demand. However, most were of poor quality, for example sewing or knitting done to keep the material together made the PPE less durable.

\section{Initiative to reality}

This experience became the initiative to find out alternatives for PPE that the healthcare teams were expected to wear. All possible opportunities were sought at the Teaching Hospital, Anuradhapura to design a safe, convenient to wear and less expensive protective garment to be used when treating patients with COVID-19 in future. The first task in this operation was to identify a low-cost yet water resistant good quality material for designing the gowns. In the hospital, the freely available yellowcoloured polyethylene bags used for biological waste disposal was identified as the most suitable material for the purpose. Thereafter, according to the Guideline for PPE issued by the Ministry of Health of Sri Lanka (5), a PPE which covers the body from head to toe was designed. This garment consists of a body cover (wraparound), head cover and a pair of foot covers.

The protective garment evolved over time with over 30 designs. It soon became popular among other healthcare staff and initiated its production at different levels and standards by many local places. The most widely manufactured design (Model - UDS 28) is outlined in Figure 1.
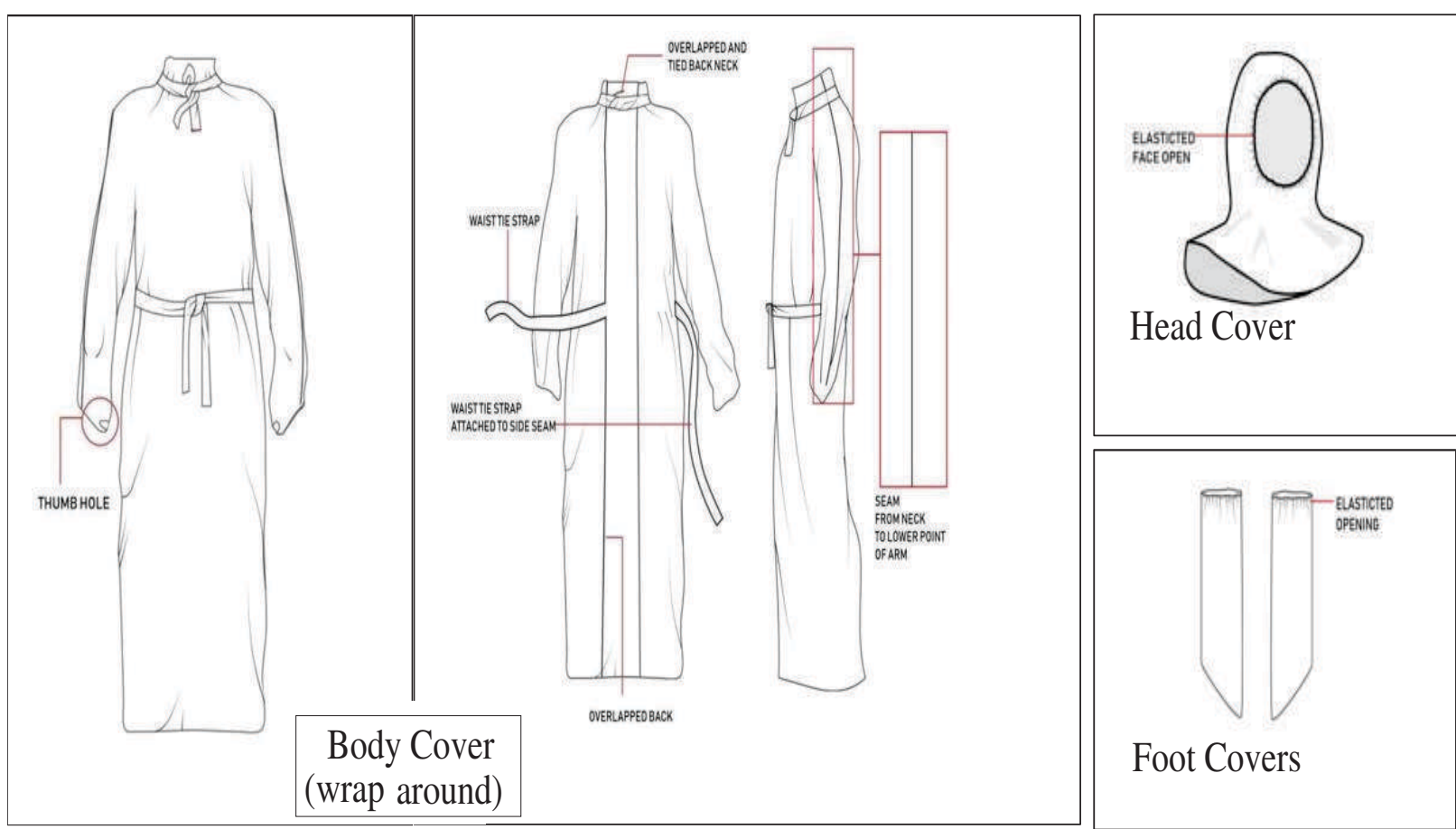

Figure 1: Most widely used personal protective garment for healthcare workers during COVID-19 epidemic

\section{Recommended standard of the PPE}

We had to ensure that the protective garment designed meets all the standards required for protection of healthcare workers who use PPE. Given below is the list of standards recommended by the Ministry of Health. 


\section{Guidelines on rational use of Personal Protective Equipment during COVID-19-}

(Annexure A: 1.2) (5)

- Impermeable to blood and body fluids

- Single use

- Avoid culturally unacceptable colours. e.g. Black

- Light colours are preferable to better detect possible contamination

- Thumb / Finger lops to anchor sleeve in place

- Quality compliant with the following standard - Meet or exceeds ISO 16603 class 3 exposure pressure or equivalent (e.g. material used in hospital biological waste disposal bag)

\section{Challenges and solutions}

The challenge was to make the protective garment waterproof (with sewing and knitting not acceptable). We had to use different methods of sealing polythene. Conventional polythene sealers, aluminium foils with electric iron, electric soldering iron with Teflon sheet and sealing with cello tape are some of the techniques that were practised during the design stage (Figure 2).

\section{Sustainability of the PPE}

The standards of the product were maintained consistently and has continued to develop improved versions of the original design. Initially, the production was done for the personal use of the paediatric ward staff. The next challenge was manufacturing it at large-scale.

The Presidential Secretariat, Ministry of Health and the Government Medical Officers Association fully supported this task to further modify the design and to initiate mass-scale production of the PPE. Currently, production of this PPE is done at largescale by Sri Lanka Army, Air force and Civil Defence along with some leading companies in the apparel industry.

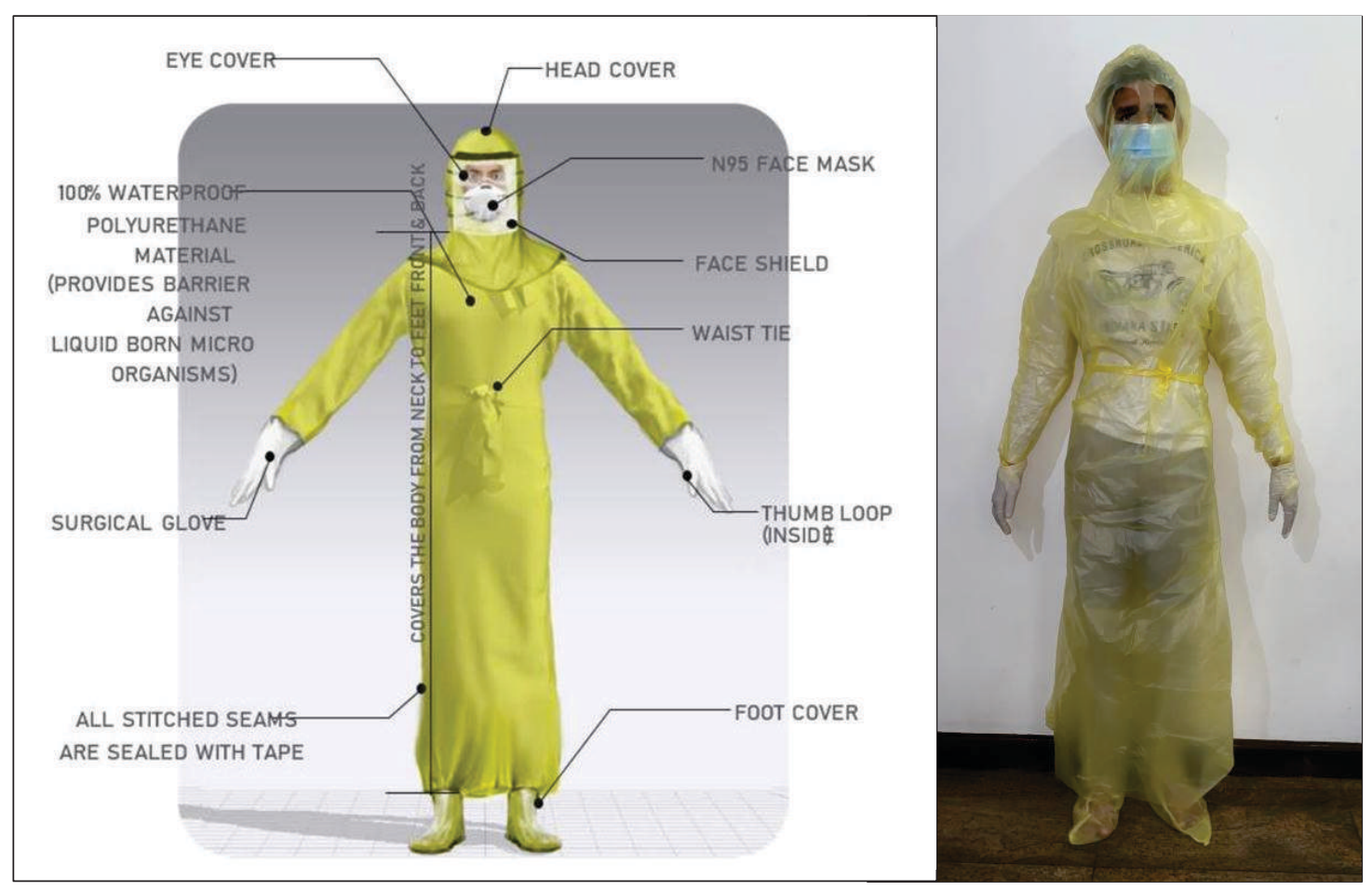

Figure 2: The newly designed protective garment 
This PPE is currently used by government hospitals, leading private hospitals, Sri Lanka Red Cross, Suwaseriya (1990) Ambulance Service and by many voluntary organisations. Supply for the Ministry of Health is approximately 1500 per day while that for Suwaseriya Ambulance Service is 1000 per day. Over Rs. 2000 per day is donated by well-wishers to require healthcare workers and involved personnel.

As the latest development, the manufacturers not only supply for the local market but also export it to the overseas market, and thereby contribute to build up the economy of Sri Lanka.

\section{Preparedness for the future}

The crisis situation became the motivation for initiating this innovation. Based on lessons learnt, it is important to have a collection of various PPE model designs with adequate supplies for future situations. Adequate material supplies should also be ensured for the manufacturing process, along with adequate utilization of manpower of the apparel industry, Army and Air Force for the current manufacturing process.

\section{Author Declaration}

Acknowledgements: Team of the doctors, nurses and the assistant staff of the Paediatric Unit A, Teaching Hospital, Anuradhapura; Dr PB Jayasundera, Secretory to the Hon. President; Ms Indika Wijegunewardena, Additional Secretary to the Hon. President; Dr Anil Jasinghe, Director General Health Services, Ministry of Health; Dr Dulan Samaraweera, Director, Teaching Hospital, Anuradhapura; and Government Medical Association

\section{References}

1. Challenges and solutions for addressing critical shortage of supply chain for personal and protective equipment (PPE) arising from Coronavirus disease (COVID19) pandemic - Case study from the Republic of Ireland. Science of the Total Environment 2020; 725: 138532. DOI: 10.1016/j.scitotenv.2020.138532.

2. COVID-19: Doctors still at "considerable risk" from lack of PPE, BMA warns. BMJ 2020; 368: m1316. DOI: $10.1136 /$ bmj.m1316.

3. Ranney ML, Griffeth V, Jha AK. Critical supply shortages - The need for ventilators and personal protective equipment during the Covid-19 pandemic. New England Journal of Medicine 2020; 382: e41. DOI: 10.1056/NEJMp2006141

4. Jacobs A, Richtel M, Baker M. 'At war with no ammo': doctors say shortage of protective gear is dire. The New York Times, 19 March 2020. Available from: https://www.nytimes.com /2020/03/19/ health/ coronavirus-masks-shortage. html.\% 20opens\%2 0in\%20new\%20tab. https://www. nytimes.com/2020/03/19/health/coronavirusmasks-shortage.html.\% 20opens\% 20in\%20new\% 20 tab.

5. Directorate General of Health Services. Novel Coronavirus Disease 2019 (COVID-19): Guidelines on rational use of personal protective equipment. Ministry of Health and Family Welfare [Emergency medical Relief]. Available from: https:// www.mohfw.gov.in/pdf/Guideline sonrational useof PersonalProtectiveEquipment.pdf. 